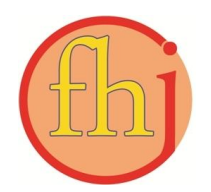

Faletehan Health Journal, 7 (2) (2020) 85-91

www. journal.Ippm-stikesfa.ac.id/ojs/index.php/FHJ

ISSN 2088-673X | e-ISSN 2597-8667

\title{
Pengaruh Terapi Bermain Terhadap Trauma Healing Pada Anak Korban Bencana Alam
}

\author{
Dhito Dwi Pramardika ${ }^{1 *}$, Jelita Siska Herlina Hinonaung ${ }^{1}$, Astri Juwita M ahihody ${ }^{1}$, \\ Grace Angel Wuaten ${ }^{1}$
}

${ }^{1}$ Program Studi Keperawatan Politeknik Negeri Nusa Utara

*Corresponding Author: dhitodwi@gmail.com

\begin{abstract}
Abstrak
Dampak dari bencana alam yaitu korban jiwa, kehilangan harta benda, dan kerusakan lingkungan. namun sering kali dampak psikologis sering diabaikan terutama pada anak-anak. Jika tidak ditanggulangi dapat berpengaruh pada tumbuh kembangnya. Oleh karena itu, penelitian ini bertujuan untuk mengetahui perbedaan pengaruh trauma healing pada anak-anak korban bencana alam tanah longsor dan banjir bandang di Kampung Belengang Kabupaten Kepulauan Sangihe Provinsi Sulawesi Utara yang diberi terapi bermain dengan yang tidak diberikan intervensi (kontrol). Jenis penelitian ini merupakan quasy experiment dengan dua sampel tidak berpasangan. Analisis yang digunakan untuk menguji perbedan pengaruh yaitu menggunakan uji Mann-Whitney. Sampel penelitian ini adalah 16 anak kelompok intervensi dan 10 anak kelompok kontrol karena menggunakan metode independent sample $t$ test. Hasil penelitian ini menunjukkan bahwa hasil selisih/beda nilai rata-rata kelompok eksperimen 17,6056 sedangkan selisih/beda nilai rata-rata kelompok kontrol 0,0000. Dapat disimpulkan bahwa ada perbedaan pengaruh yang signifikan antara anak yang diberi terapi bermain dengan kelompok kontrol $(p=0,000)$.

Kata Kunci: Bencana Alam, Terapi bermain, Trauma healing
\end{abstract}

\section{Effects of Play Therapy on Trauma Healing in Children Victims of Natural Disasters}

\begin{abstract}
The impact of natural disasters is loss of life, loss of property, and environmental damage. However, the psychological impact is often ignored especially in children. If not addressed, it can affect on their growth and development. This study aims to determine the effects of trauma healing on children victims of landslides and flash floods in Kampung Belengang, Sangihe Islands Regency, North Sulawesi Province. The experimental group were given play therapy while the control group were not given the intervention. The type of research is quasi-experimental with two unpaired samples. The analysis used to test the difference of the effects is by using Mann-Whitney test. The samples of this study were 16 children in the experimental group and 10 children in the control group. The results of this study show the difference in the average value of the experimental group (17.6056) and the average value of the control group (0.0000). To conclude, there is a significant difference between children who are given play therapy and the control group $(\mathrm{p}=0.000)$.
\end{abstract}

Keywords: Play Therapy, Trauma Healing, Natural Disasters 


\section{Pendahuluan}

Berdasarkan data Rangkuman sepanjang tahun 2019 bahwa di Indonesia telah terjadi sebanyak 3.721 bencana yang diantaranya akibat 1.339 puting beliung, 746 kebakaran hutan dan lahan, 757 banjir, 702 tanah longsor dan lainnya (Azanella, 2019). Berdasarkan data juga diketahui bahwa 60-70\% korban bencana adalah perempuan dan anak (Setiawan, 2019).Siapapun itu tidak menginginkan terjadinya bencana alam. Bencana alam menurut UU Nomor 24 Tahun 2007 terjadi karena faktor alam dan atau non alam maupun karena faktor manusia itu sendiri yang dapat mengakibatkan timbulnya korban jiwa manusia, kerusakan lingkungan, kerugian harta benda dan dampak psikologis (Indonesia, 2007).

Bulan Januari 2020 Kabupaten Kepulauan Sangihe mengalami bencana alam banjir bandang dan tanah longsor. Bencana tersebut menyebabkan sebanyak 106 jiwa masyarakat kampung Belengang mengungsi, dengan rincian sebanyak 53 jiwa mengungsi di posko pengungsian, sementara 53 jiwa lainnya mengungsi ke rumah saudara terdekat yang tidak terkena bencana. Anak-anak korban bencana alam yang terdata yaitu anak SD sebanyak 18 orang, SMP sebanyak 6 orang dan SMA sebanyak 8 orang, serta terdapat 3 balita akibat bencana alam tersebut.

Banyaknya jumlah anak-anak pengungsi perlu mendapatkan perhatian terutama pada masalah psikologis (Kemdikbud, 2018). Masalah psikologis ini berupa Posttraumatic Stress Disorder (PTSD). Hasil penelitian pada gempa Lombok menyatakan bahwa 14,89\% anak korban bencana mengalami kecemasan klinis (Thoyibah dkk., 2019). Dampak yang dinyatakan pada penelitian yang menyatakan bahwa pertumbuhan dan perkembangan anak usia 3-24 bulan yang tinggal di daerah konflik, pada pertumbuhan anak anak kurus sebesar 32\%, dan lingkar kepala tidak normal sebesar $17 \%$. Sedangkan pada perkembangan perkembangan anak meragukan sebesar 30\% (Usman dkk., 2014). Sementara anak-anak tersebut mempunyai hak yang diatur oleh negara pada Undang-Undang No. 35 tahun 2014 untuk mendapatkan penanganan terdampak dalam keadaan darurat (Indonesia, 2014).
Untuk mengurangi dampak dari trauma yang diakibatkan oleh bencana alam tersebut diberikan terapi bermain sebagai intervensi trauma healing pada anak. Pada sebuah penelitian menyatakan bahwa play therapy merupakan sebuah terapi yang mampu menangani anak pasca trauma bencana untuk menghibur dan mengatasi masalah yang diderita melalui bermain (Dzulfaqori, 2017). Pada hasil penelitian lainnya menyatakan hal yang serupa yaitu terapi bermain mewarnai efektif untuk menurunkan stres hospitalisasi pasien anak usia prasekolah $(\mathrm{p}=0,0295)$ (Lailiyati, 2018). Terapi bermain mewarnai merupakan salah satu metode permainan berbasis relaksasi sedangkan permainan bernyanyi, balon, kelereng dan ular tangga merupakan diantara permainan yang berbasis pada metode kebahagiaan (Kemdikbud, 2018).

Berdasarkan hal tersebut, penelitian ini dilakukan dengan tujuan untuk mengetahui pengaruh terapi bermain terhadap trauma healing pada anak korban bencana alam Kampung Belengang Kecamatan Manganitu Kabupaten Kepulauan Sangihe provinsi Sulawesi Utara.

\section{Metode Penelitian}

Jenis penelitian ini adalah penelitian quasy eksperiment dengan desain non equivalent control group. Desain ini untuk mengetahui perbedaan keadaan awal antara kelompok eksperimen dan kelompok kontrol. Pada penelitian eksperimen dan kontrol merupakan anak-anak dari korban bencana alam tanah longsor dan banjir di kampung Belengang. Pada kelompok eksperimen sebelumnya diberikan pretest dan kemudian diberikan intervensi selama seminggu berupa terapi bermain dan dilanjutkan kembali dengan memberikan posttest. Sedangkan pada kelompok kontrol dilakukan juga pretest namun tidak diberikan terapi apapun dan seminggu kemudian diberikan kembali posttest.

Lokasi penelitian ini adalah Gereja GMIST Belengang sebagai posko pengungsi warga Kampung Belengang Kecamatan Manganitu Kabupaten Kepulauan Sangihe Provinsi Sulawesi Utara yang dilaksanan pada bulan Januari 2020. Populasi penelitian ini adalah anak-anak korban bencana alam banjir bandang dan tanah longsor di Kampung Belengang yaitu sebanyak 35 orang. 
Faletehan Health Journal, 7 (2) (2020) 85-91

www. journal.Ippm-stikesfa.ac.id/ojs/index.php/FHJ

ISSN 2088-673X | 2597-8667

Namun dikarenakan ada 9 anak yang mengungsi ke rumah keluarganya yang jauh dari lokasi sehingga total populasi pada penelitian ini menjadi 26 orang.

Besar sampel pada penelitian ini yaitu menggunakan teknik total sampling. Kemudian pembagian kelompok dilakukan dengan teknik pengambilan secara purpossive yaitu 16 orang kelompok eksperimen yaitu anak-anak yang tinggal di posko pengungsian dan 10 orang kelompok kontrol yaitu anak-anak yang tidak tinggal di posko pengungsian melainkan rumah saudara yang lokasinya tidak jauh dari lokasi posko pengungsian. Jumlah sampel berbeda karena penelitian ini merupakan independent sample $t$ test, dimana antara sampel tidak berpasangan. Sampel yang aktif mengikuti terapi bermain dan sampel yang berdiam dirumah.

Terapi bermain yang diberikan yaitu berupa bernyanyi bersama, bermain balon, bermain kelereng, bermain ular tangga dan mewarnai. Permainan bernyanyi yaitu dengan menyanyikan lagu "apa kabar". Permainan ini dilakukan dengan cara berpasangan. Kemudian masing-masing pasangan akan bernyanyi disertai gerakan. Diakhir permainan pasangan ini akan berpisah dan cepat-cepatan mencari pasangan yang lain. Siapa yang tidak mendapatkan pasangan maka dia akan keluar dari permainan ini. Kemudian dilanjutkan dengan bermain balon yaitu berupa anak-anak mendengarkan musik yang dinyanyikan bersama antara tim peneliti dan anakanak, kemudian anak diberikan satu buah balon dan diberikan instruksi untuk memberikan balon tersebut ke teman di sebelahnya dan jika musik berhenti dan siapapun yang masih memegang balon tersebut maka dia keluar dari permainan. Permainan berikutnya yaitu bermain kelereng. Cara permainan ini yaitu peserta menggigit sebuah sendok yang diatasnya telah diletakkan sebuah kelereng. Kemudian peserta berlari menuju garis finish yang telah ditentukan. Kelereng peserta yang terjatuh sebelum mencapai garis finish, maka peserta tersebut kalah.Permainan lainnya yang diberikan yaitu ular tangga merupakan permainan jenis papan yang terbuat dari kertas yang terdapat beberapa hambatan. Dimainkan menggunakan dadu oleh beberapa orang. Permainan terakhir yang diberikan yaitu terapi bermain dengan metode relaksasi yaitu dengan cara mewarnai sebuah sketsa gambar. Sketsa yang disukai dan diketahui oleh anak-anak seperti upin-ipin, hewan dan pemandangan.

Peralatan yang digunakan dalam permainan seperti balon, karet, kelereng, sketsa gambar, pensil warna, ular tangga dan kuesioner. Kuesioner yang digunakan pada penilaian trauma pretest dan posttest yaitu menggunakan kuesioner PTSD yang telah dimodifikasi dengan realibilitas yaitu 0,819 dengan nilai $r$ tabel 0,3438 .

Analisis data yang digunakan adalah analisis univariat dan analisis bivariat. Analisis univariat dilakukan untuk mengetahui distribusi frekuensi dan persentase setiap variabel. Sedangkan uji bivariat yang digunakan yaitu untuk mengetahui pengaruh terapi bermain terhadap trauma healing yaitu dengan menguji beda rata-rata menggunakan uji independent $t$-test.

\section{Hasil dan Pembahasan}

\section{A. Karakteristik Responden}

1. Usia

Berdasarkan tabel 2 menjelaskan bahwa rata-rata seluruh responden berusia 10 tahun dan secara keseluruhan anak korban bencana alam di kampung Belengang yang paling banyak yaitu pada usia kanak-kanak sebanyak 15 responden (57,69\%). Pada kelompok eksperimen rata-rata berusia11,25 tahun paling banyak yaitu pada usia kanak-kanak (5-11 tahun) dan usia remaja awal (12-16 tahun) yaitu masing-masing sebesar (43,75\%) sedangkan responden yang paling sedikit yaitu berusia remaja akhir (17-25 tahun) sebanyak 2 responden (12,5\%). Pada kelompok kontrol ratarata berusia 8 tahun dan usia paling banyak menjadi responden yaitu pada usia kanak-kanak (5-11 tahun) sebanyak 8 responden (80\%) sedangkan responden yang paling sedikit yaitu berusia Balita (0-5 tahun) sebanyak 2 responden (20\%). Terapi bermain dapat dilakukan tidak hanya terbatas pada usia todler tetapi juga dapat dilakukan pada usia anak SMA (Kemdikbud, 2018).

\section{Jenis Kelamin}

Dari tabel 1 juga dijelaskan bahwa pada kelompok eksperimen jenis kelamin yang paling banyak jadi responden adalah perempuan yaitu sebanyak 12 responden $(75 \%)$ sedangkan responden berjenis kelamin laki-laki sebanyak 4 responden $(25 \%)$. Pada kelompok kontrol jenis kelamin paling banyak yang menjadi responden adalah laki-laki yaitu sebanyak 8 responden 
Tabel 1. Distribusi Frekuensi Karakteristik Responden

\begin{tabular}{|c|c|c|c|c|}
\hline \multirow{2}{*}{ Karakteristik } & \multicolumn{2}{|c|}{ Kelompok eksperimen } & \multicolumn{2}{|c|}{ Kelompok Kontrol } \\
\hline & $\mathrm{n}$ & $\%$ & $\mathrm{n}$ & $\%$ \\
\hline \multicolumn{5}{|l|}{ Usia } \\
\hline Balita (0-5 tahun) & 0 & 0 & 2 & 20 \\
\hline Kanak-kanak (5-11 tahun) & 7 & 43,75 & 8 & 80 \\
\hline Remaja awal (12-16 tahun) & 7 & 43,75 & 0 & 0 \\
\hline Remaja akhir (17-25 tahun) & 2 & 12,5 & 0 & 0 \\
\hline \multicolumn{5}{|l|}{ Jenis Kelamin } \\
\hline Laki-laki & 4 & 25 & 8 & 80 \\
\hline Perempuan & 12 & 75 & 2 & 20 \\
\hline \multicolumn{5}{|l|}{ Pendidikan } \\
\hline PAUD & 0 & 0 & 2 & 20 \\
\hline SD & 9 & 56,25 & 8 & 80 \\
\hline SMP & 5 & 31,25 & 0 & 0 \\
\hline SMA & 2 & 12,5 & 0 & 0 \\
\hline
\end{tabular}

(80\%) sedangkan responden perempuan sebanyak 2 responden (20\%) secara keseluruhan anak korban bencana alam di kampung Belengang yang paling banyak adalah berjenis kelamin perempuan yaitu sebanyak 14 responden $(53,85 \%)$

\section{Pendidikan}

Berdasarkan tabel 1 distribusi frekuensi untuk pendidikan pada kelompok eksperimen adalah pada responden yang saat ini belajar pada pendidikan kelas SD yaitu sebanyak 9 responden $(56,25 \%)$, SMP sebanyak 5 responden $(31,25 \%)$ dan SMA sebanyak 2 responden (12,5\%). Pada kelompok kontrol yang terbanyak menjadi responden adalah responden yang saat ini belajar pada pendidikan kelas SD yaitu sebanyak 8 responden $(80 \%)$ dan PAUD sebanyak 2 responden $(20 \%)$. Secara keseluruhan yang menjadi responden terbanyak pada penelitian ini adalah anak-anak yang saat ini belajar pada pendidikan kelas SD sebanyak 17 responden $(65,48 \%)$.

\section{B. Terapi Bermain Terhadap Trauma Healing Pada Anak Korban Bencana Alam}

1. Distribusi frekuensi hasil penelitian

Berdasarkan tabel 2 diketahui bahwa rata-rata nilai pretest pada kelompok pretest eksperimen adalah 58,3319 (SD 6,6660), kemudian hasil pretest pada kelompok kontrol dengan nilai ratarata 63,9990 (SD9,46737). Kemudian hasil nilai posttest pada kelompok eksperimen dengan nilai rata-rata 75,9375 (SD 11,3018) dan nilai rata-rata posttest pada kelompok kontrol adalah 64,9990 (SD 8,71334).

Tabel 2. Hasil Uji Deskriptif trauma healing

\begin{tabular}{lccc}
\hline Hasil Kelompok & N & Mean & Standar Deviasi \\
\hline Pretest eksperimen & 16 & 58,3319 & 6,6660 \\
\hline Pretest kontrol & 10 & 63,9990 & 9,46737 \\
\hline Posttest eksperimen & 16 & 75,9375 & 11,3018 \\
\hline Posttest kontrol & 10 & 64,9990 & 8,71334 \\
\hline
\end{tabular}

Tabel 3. Menyajikan data mengenai selisih/beda pada terapi bermain dan yang tidak. Pada kelompok eksperimen yang diberikan perlakukan terapi bermain diketahui bahwa nilai rata-rata dari selisih/beda pre posttest adalah 17,6056 dengan standar deviasi sebesar 9,84914. Sedangkan nilai rata-rata dari selisih/beda pre post kelompok kontrol adalah 0,0000 (SD 0,00000).

Tabel 3. Deskriptif selisih/beda trauma healing

\begin{tabular}{lccc}
\hline Hasil Kelompok & $\mathrm{N}$ & Mean & Standar Deviasi \\
\hline Eksperimen & 16 & 17,6056 & 9,84914 \\
\hline Kontrol & 10 & 0,0000 & 0,00000 \\
\hline
\end{tabular}

\section{Uji Normalitas}

Dari tabel 4 diketahui bahwa semua hasil nilai pada kelompok eksperimen dan kelompok kontrol pada uji kolmogorov-smirnov dan menggunakan uji shapiro-wilk adalah nilai $p$ value $>0,05$, yang artinya bahwa data pada penelitian ini pada kelompok eksperimen dan pada kelompok kontrol, keduanya data berdistribusi normal. 
Faletehan Health Journal, 7 (2) (2020) 85-91

www. journal.Ippm-stikesfa.ac.id/ojs/index.php/FHJ

ISSN 2088-673X | 2597-8667

Tabel 4. Hasil Uji Normalitas trauma healing

\begin{tabular}{cccc}
\hline Hasil Kelompok & $\begin{array}{c}\text { Kolmogorov } \\
\text {-Smirnov }\end{array}$ & $\begin{array}{c}\text { Shapiro } \\
\text {-Wilk }\end{array}$ & Kesimpulan \\
\cline { 2 - 4 } & $p$ value & $p$ value & \\
\hline Pretest Eksperimen & 0,200 & 0,305 & Normal \\
\hline Pretest Kontrol & 0,200 & 0,510 & Normal \\
\hline Posttest Eksperimen & 0,200 & 0,952 & Normal \\
\hline Posttest Kontrol & 0,168 & 0,191 & Normal \\
\hline
\end{tabular}

Tabel 5. Hasil Uji Normalitas selisih/beda trauma healing

\begin{tabular}{cccc}
\hline Hasil Kelompok & $\begin{array}{c}\text { Kolmogorov } \\
\text {-Smirnov }\end{array}$ & $\begin{array}{c}\text { Shapiro } \\
- \text { Wilk }\end{array}$ & Kesimpulan \\
\cline { 2 - 4 } & $p$ value & $p$ value & \\
\hline Eksperimen & 0,003 & 0,000 & Tidak Normal \\
\hline Kontrol & 0,000 & 0,000 & Tidak Normal \\
\hline
\end{tabular}

Tabel 5. Menjelaskan bahwa nilai selisih/beda pada pre posttest pada kelompok eksperimen dan kontrol setelah dilakukan pengujian normalitas menggunakan kolmogorovsmirnov dan shapiro-wilk bahwa data tidak berdistribusi normal karena $p$ value $<0,05$ sehingga untuk selisih/beda trauma healing akan dilakukan berikutnya menggunakan statistik non parametrik menggunakan uji Mann-Whitney.

\section{Uji Mann-Whitney}

Berdasarkan tabel 6 dapat diketahui bahwa nilai $p$ value adalah $0,000<0,05$ yang artinya terdapat perbedaan pengaruh trauma healing pada anak yang diberikan terapi bermain dengan anakanak yang tidak diberikan terapi bermain pada anak korban bencana alam Kampung Belengang Kecamatan Manganitu Kabupaten Kepulauan Sangihe.

Tabel 6. Perbedaan pengaruh trauma healing antara terapi bermain dan yang tidak diberikan perlakuan

\begin{tabular}{|l|l|}
\hline & Selisih/beda \\
\hline Asymp. Sig. (2-tailed) & 0,000 \\
\hline
\end{tabular}

Adanya pengaruh trauma healing pada anak yang diberikan terapi bermain dengan yang tidak pada penelitian ini sejalan dengan hasil penelitian yang menyatakan bahwa terapi bermain mewarnai efektif untuk menurunkan stres hospitalisasi pasien anak usia prasekolah (Lailiyati, 2018). Faktor-faktor yang mempengaruhi pemulihan trauma salah satunya adalah dari faktor lingkungan yaitu berupa dukungan masyarakat dan dukungan berkelanjutan dari para profesional seperti dokter, konselor, guru dan sebagainya) serta adanya hubungan individu tersebut dengan orang lain. Terapi bermain yang diberikan merupakan termasuk dalam faktor tersebut (Laluyan, 2007).

Terapi bermain merupakan proses terapeutik dengan menggunakan media permainan sebagai terapi agar mudah melihat ekspresi alami seorang anak yang tidak bisa diungkapkannya dalam bahasa verbal. Terapi bermain juga dapat menghilangkan beberapa permasalahan diantaranya seperti kecemasan, menghilangkan batasan, hambatan dalam diri, frustasi serta mempunyai masalah pada emosi yang bertujuan untuk mengubah tingkah laku anak yang kurang sesuai menjadi tingkah laku yang sesuai dan diharapkan sehingga anak dapat bermain dan lebih kooperatif dan dapat mudah diajak untuk kerjasama ketika menjalani terapi (Noverita, 2017)

Terapi bermain yang diberikan berupa kegiatan bernyanyi bersama. Kegiatan tersebut dapat menyalurkan ekspresi yang terdapat pada diri anak dan dapat membangun koneksi dengan orang lain. Hal itu sesuai dengan pernyataan yang menyatakan bahwa kegiatan bernyanyi dapat membantu perkembangan anak dalam artikulasi pada keterampilan bahasa, irama, dan kontrol pernapasan. Kemudian apabila kegiatan tersebut diikuti dengan gerak ritmis, maka gerak ritmis tersebut bermanfaat dalam mengembangkan jangkauan fisiologis, menggabungkan mobilitas/ meningkatkan ketangkasan dan kekuatan serta keseimbangan, meningkatkan koordinasi, 
konsistensi, pola-pola pernapasan, dan juga relaksasi pada otot (Djohan, 2006).

Permainan mewarnai diberikan pada anakanak yang memasuki usia kanak-kanak (5-11 tahun). Permainan ini bertujuan untuk meningkatkan kreativitas dan juga merupakan terapi relaksasi bagi anak-anak karena warna yang sering muncul pada sebuah gambar banyak emosi didalamnya. Dan dengan menciptakan gambar atau lukisan yang hanya menggunakan warna yang anak sukai dapat menenangkan dirinya. Kemudian dengan anak-anak diberi kebebasan untuk mewarnai juga merupakan salah satu terapi karena tidak ada acara salah dan benar dalam membuat seni (Kemdikbud, 2018). Aktivitas bermain meawarnai yang dilakukan anak-anak dapat mengalihkan rasa trauma dan juga anakanak mendapat efek relaksasi dari kegiatan tersebut melalui kesenangannya yaitu melakukan permainan (Supartini, 2004).

Selain itu diberikan juga terapi bermain dengan kegiatan yang berfokus pada peningkatan kompetisi pada diri anak seperti bermain kelereng, bermain balon, bermain karet, bermain ular tangga juga diberikan dalam terapi ini. Permainan kompetisi diperlukan agar anak mampu mengeksplorasi dan menguasai sesuatu serta membangun kepercayaan dengan menunjukkan bahwa anak yang sedang melakukan kerja dan menunjukkan kemajuan. Selain itu, permainan yang diberikan tersebut juga dapat mempengaruhi perkembangan kepribadian yang diinginkan yaitu dari hubungan dengan anggota kelompok teman sebaya dalam bermain, anak belajar bekerja sama, murah hati, jujur, sportif dan disukai orang (Hurlock, 2008). Dengan berbagai permainan tersebut dapat menciptakan suasana yang menyenangkan untuk trauma healing karena anakanak dapat tertawa bersama (Kemdikbud, 2018).

Masa kanak-kanak seharusnya memberikan kenangan yang manis dan berkesan baik sehingga dapat memberikan dampak positif bagi pertumbuhan dan perkembangan anak, namun sebaliknya yang dialami oleh anak-anak korban bencana banjir bandang dan tanah longsor, mereka mengalami kenangan traumatis yang mungkin sulit dilupakan (Famula, 2007). Hal itu sesuai dengan analisis pada kelompok kontrol yang menyatakan tidak terjadi peningkatan pada trauma healing. Karena berdasarkan hasil observasi situasi dan kondisi di lapangan bahwa mereka yang tinggal bersama dengan orang lain untuk mengungsi memiliki keterbatasan dalam dalam beraktivitas dan interaksi mereka terhadap orang lain pun hanya dengan orang tua mereka.

\section{Simpulan}

Penelitian ini menunjukkan ada perbedaan pengaruh yang signifikan terhadap trauma healing pada anak korban bencana alam antara anak yang diberikan terapi bermain dengan yang tidak diberikan terapi bermain.

\section{Referensi}

Azanella, L. A. (2019). Sepanjang 2019, BNPB Catat 3.721 Bencana Alam Terjadi di Indonesia. Kompas.com. https://www.kompas.com/tren/read/2019/12/ 23/183700665/sepanjang-2019-bnpb-catat3.721-bencana-alam-terjadi-di-indonesia

Djohan. (2006). Terapi Musik “ Teori dan Aplikasi. Galang Press.

Dzulfaqori, I. S. (2017). Konseling pada Anak Korban Bencana Alam: Play Therapy Perspektif. 122.

Famula, K. (2007). Healing Societal Traumas and Transforming Collective Conciusness A Path to Culture of Healing. European University Center for Peace Studies Standtschlaning/ Burg.

Hurlock, E. B. (2008). Psikologi Perkembangan Suatu Pendekatan Sepanjang Rentang Kehidupan (5 ed.). Erlangga.

Indonesia. (2007). Undang-Undang Republik Indonesia Nomor 24 Tahun 2007 tentang Penanggulangan Bencana. Dewan Perwakilan Rakyat Republik Indonesia.

Indonesia. (2014). Undang-Undang No. 35 Tahun 2014 tentang Perlindungan Anak.

Kemdikbud. (2018). Modul Bimbingan Teknnis Pemulihan Trauma (Trauma Healing) Bagi Kepala Sekolah dan Pengawas Sekolah Pasca Bencana Kota Palu, Kab. Donggala, Kab. Sigi Provinsi Sulawesi Tengah. Kementerian Pendidikan dan Kebudayaan Direktorat Jenderal Guru dan Tenaga Kependidikan Direktorat Pembinaan Tenaga Kependidikan.

Lailiyati, N. (2018). Terapi Bermain Mewarnai Untuk Menurunkan Stres Hospitalisasi Pada Pasien Anak Usia Prasekolah. Fakultas Ilmu Sosial dan Humaniora Universitas Islam Negeri Sunan Kalijaga Yogyakarta. 
Faletehan Health Journal, 7 (2) (2020) 85-91

www. journal.Ippm-stikesfa.ac.id/ojs/index.php/FHJ

ISSN 2088-673X | 2597-8667

Laluyan, T. (2007). Pemulihan Trauma: Panduan Praktis Pemulihan Trauma Akibat Bencana Alam. Lembaga Pengembangan Sarana Pengukuran dan Pendidikan Psikologi Fakultas Psikologi Universitas Indonesia.

Noverita, M. D. (2017). Terapi Bermain Terhadap Tingkat Kecemasan pada Anak Usia 3-5 Tahun yang Berobat di Puskesmas. Jurnal Ilmu Keperawatan, 5(2). http://jurnal.unsyiah.ac.id/JIK/article/view/10 $539 / 8323$

Setiawan, R. (2019). BNPB: 60 Sampai 70\% Korban Bencana Adalah Perempuan dan Anak. tirto.id. https://tirto.id/dgod
Supartini, Y. (2004). Buku Ajar Konsep Dasar Keperawatan Anak. EGC.

Thoyibah, Z., Dwidiyanti, M., Mulianingsih, M., Nurmayani, W., \& Wiguna, R. I. (2019). Gambaran Dampak Kecemasan dan Gejala Psikologis pada Anak Korban BencanabGempa Bumi di Lombok. Journal of Holistic Nursing and Health Science, 2(1), 31-38.

Usman, H., Hadyana, S., \& Ma'mun, S. (2014). Pertumbuhan dan Perkembangan Anak Usia 3-24 Bulan di Daerah Konflik. Jurnal Kesehatan Masyarkat Nasional, 9(1). http://dx.doi.org/10.21109/kesmas.v9i1.455 